A AUTORA

Maria Elisa Vercesi de Albuquerque

Pesquisadora do IDART/Divisão de Pesquisas ${ }^{1}$

Mestre em Ciências Sociais pela UNICAMP

\title{
PESQUISA E MEMÓRIA DA ARTE EM SÃO PAULO
}

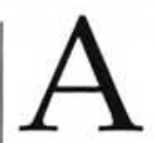

Divisão de Pesquisas do Centro Cultural São Paulo/IDART é uma instituição voltada para o registro das manifestações artísticas brasileiras, produzidas ou veiculadas na cidade de São Paulo, sob a perspectiva do futuro, isto é, identificando percursos da arte e da cultura que contenham significados da contemporaneidade para constituírem a memória de nosso tempo.

Seu acervo vem sendo formado com a coleta e preservação de documentos e produção de pesquisas temáticas nas áreas de Arquitetura, Artes Cênicas, Artes Gráficas, Artes Plásticas, Cinema, Comunicação de Massa, Fotografia, Literatura e Música.

O diferencial com relação a outras instituições é exatamente a abordagem do fazer artístico e cultural no momento mesmo de sua produção, com a possibilidade de atuação interdisciplinar. Depois de 27 anos de trabalho prático permanente, pode-se dizer que já existe uma tradição de coleta de informações, de documentos, de depoimentos, de sons, de imagens que, por sua vez, geram textos reflexivos, projetos de pesquisas, seminários, exposições, bases de dados e outros.

\section{PROJETO ORIGINAL}

Essa iniciativa ousada e inovadora - até para os dias de hoje - teve início no Centro de Documentação e Informação sobre Arte Brasileira Contemporânea do IDART, departamento implantado pela Secretaria Municipal de Cultura, em maio de 1975.

A primeira sede foi a Casa da Marquesa, construção histórica recém restaurada, que já abrigava a própria Secretaria da Cultura. Ali passaram a se reunir artistas, intelectuais, pesquisadores especializados e muitos iniciantes, todos entusiasmados com a proposta inédita e generosa de uma instituição que vinha, de certa maneira, propiciar novas fontes, principalmente a estudantes de pós-graduação. 
Estes seminários têm enriquecido muito a reflexão interdisciplinar além de manter vivo o contato com outros especialistas. A Revista D'Art, publicação semestral, tem sido um canal de extroversão dos temas em debate na Divisão de Pesquisas, com divulgação de projetos em andamento, textos analíticos, críticas e outras manifestações, tanto dos pesquisadores da Divisão quanto de convidados.

Outro exemplo desse processo de abertura é a utilização da Internet para difusão do material gerado por pesquisas, bases de dados e documentação. No site do Centro Cultural São Paulo (www.prodam.sp.gov.br/ ccsp) é possível acessar a relação de materiais do Arquivo Multimeios, a coleção da Revista D'Art, exposições virtuais (TV Brasil Ano 50, Imagens de Dança e outras), textos integrais de livros esgotados através da Biblioteca Virtual (como é o caso de Circo: espetáculo de periferia, de 1981) e, em breve, estará concluída a adequação de bases de dados das equipes técnicas de pesquisa, para serem inseridos na rede.

Outros projetos envolvem a busca de parcerias e convênios com outras instituições afins, que possibilitem maior alcance do trabalho da Divisão de Pesquisas e do Centro Cultural São Paulo.

\section{ARQUIVO MULTIMEIOS}

A diversidade de temas e originalidade documental, resultante do trabalho das equipes, é o que confere a esse arquivo a sua especificidade como fonte de pesquisa. Além de consultas diárias feitas por estudiosos, esse acervo tem servido como informação e referência para mais de 50 títulos publicados pela Divisão de pesquisas e para diversos livros publicados por editores comerciais.

\section{$\mathrm{O}$ atual acervo do Arquivo} Multimeios disponibiliza cerca de 900 mil documentos, em diferentes suportes.

São registros visuais (negativos, contatos, ampliações, slides, microfilmes), audiovisuais (fitas de áudio, videoteipes, filmes $16 \mathrm{~mm}$, super $8 \mathrm{~mm}$, CDs) e documentos como: catálogos, programas, folhetos, press releases, convites, cartazes, fotos publicitárias, mapas, plantas, scripts, roteiros, textos de pesquisa e outros. Os materiais são processados tecnicamente e guardados em espaço equipado com instrumentos de controle de temperatura, umidade relativa do ar e gases poluentes, de acordo com normas de preservação recomendadas pelas instituições museológicas internacionais.

O Arquivo Multimeios funciona de segunda a sexta-feira, atendendo ao público das $10 \mathrm{~h}$ às $17 \mathrm{~h}$. $\mathrm{O}$ consulente conta com serviços de reprodução de material em papel, duplicação de fotos e fitas sonoras, exibição de filmes e vídeos. Conforme o caso, é necessário agendar a consulta pelo telefone (11) 3277-3611 ramais 262 e 264 , já que o material escolhido permanece na antecâmara por 24 horas, para aclimatação.

\section{LINHAS DE PESQUISA}

\section{Arquitetura}

A produção contemporânea tem sido levantada, estudada, documentada e analisada com o objetivo de promover uma reflexão sobre a cultura arquitetônica paulistana e identificar suas principais tendências. Alguns trabalhos desenvolvidos 
refletem a ampla gama de indagações da equipe, e vão da pesquisa historiográfica (Brás espaço e uso; Trajetórias da arquitetura modernista; Quadro de referências; Marcos arquitetônicos) à temática (São Paulo 1982; Arquitetura do medo) à documentação (Vale do Anhangabaú; O edifício público no setor cultural - teatros distritais; Franz Heep: perfil de arquiteto), além do banco de dados sobre a produção arquitetônica paulistana, em constante processamento.

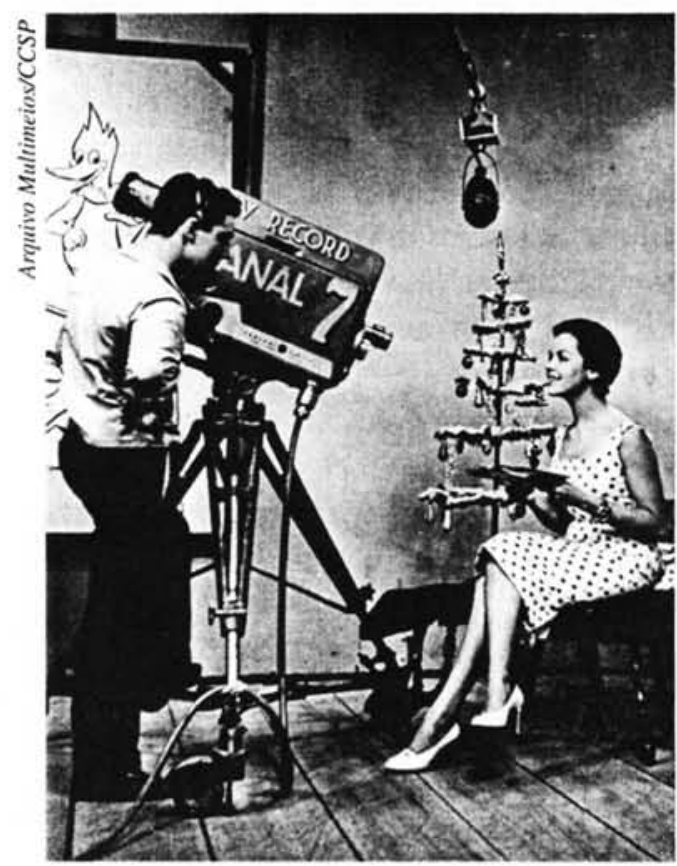

Idalina de Oliveira, garota propaganda, em estúdio da TV Record, década de 50.

\section{Artes Cênicas}

$\mathrm{O}$ acervo sobre a linguagem do teatro $\mathrm{e}$ da dança na cidade de São Paulo tem sido construído, desde 1975 , por meio da documentação de espetáculos representativos (registros fotográficos, gravações sonoras, depoimentos), com o registro sistemático das estréias (Anuário das Artes
Cênicas, Base de dados) e com a realização de pesquisas sobre aspectos específicos desse universo (cenografia do início do século XX, Teatro de Revista, Teatro de grupo dos anos 70, e outras). O material gerado tem sido também utilizado para produzir exposições, vídeo (Viagem ao umbigo da cidade), filme (Uma atriz se prepara), exposição virtual (Imagens de dança) e publicações (Circo: espetáculo de periferia; Corpo de Baile Municipal; Teatro operário na cidade de São Paulo; Sobre o trabalho do ator; Imagens do teatro paulista; Fredi Kleeman: foto em cena, entre outras)

\section{Artes Gráficas}

Tem como universo o design, tanto gráfico como de produto. Realiza a análise da linguagem visual e suas implicações no contexto da cidade, seja através de fenômenos de natureza artesanal ( $\mathrm{O}$ balão: arte do ar e do fogo; Grafite na cidade de São Paulo; Pipas e papagaios) nos projetos de âmbito industrial (O cartaz em São Paulo; Análise visual comparativa de doze jornais em São Paulo; Gráfica na TV), ou através da documentação de diversas gerações de criadores que interferiram na paisagem urbana, desde os pioneiros dos anos 50 até os designers da era da informática (A Criação gráfica 70/90 - Um olhar sobre três décadas). A equipe alimenta permanentemente uma base de dados sobre a atividade em São Paulo, complementada por um glossário.

\section{Artes Plásticas}

A documentação do processo criativo e o registro das manifestações e eventos ligados às artes plásticas na cidade produziram um grande acervo de imagens e ou- 
tros documentos. Entre os principais trabalhos constam a documentação de ciclos de performance, a arte xerox, a videoarte, dossiês de artistas formadores (Júlio Plaza, Lygia Pape, Nelson Leirner, Regina Silveira e outros) e de artistas emergentes (José Leonilson, Leda Catunda e outros). Desde os anos 90 , a pesquisa tem enfocado manifestações fora do circuito comercial (como é o caso de O Grafite em São Paulo). Alguns trabalhos da área: Performance; O Grupo Guanabara; Situação atual da escultura na cidade de São Paulo; Coleção Biblioteca de Arte: desenhos, aquarelas e guaches; Os mestres da fachada, Anuários das Artes Plásticas e Banco de dados.

\section{Cinema}

Pesquisa temas contemporâneos, aspectos da história cinematográfica do país e, desde os anos 80 , aspectos da comercialização, distribuição e consumo de cinema na cidade de São Paulo. O acervo é diversificado, graças à coleta de cartazes, fotos e press-releases, documentação de makingoff de longas-metragens (Marvada carne; Eles não usam black-tie e outros), a depoimentos de cineastas e à formação de bases de dados sobre a filmografia brasileira (Projeto indexação; Guia de filmes 1967/80 e Cinema artesanal). Alguns trabalhos da área: $\mathrm{O}$ cinema marginal; Roberto Santos: 23 anos após $O$ grande momento e Amantes da chuva; $O$ imaginário da boca; $\mathrm{O}$ documentário em São Paulo 1977-1980; As salas de cinema em São Paulo.

\section{Comunicação de Massa}

Apesar da abrangência, essa área criou um vínculo mais forte com a memória do rádio e da TV, dada a realização de pesquisas inéditas e grande quantidade de documentos coletados. A partir dos anos 80 , o registro de programas e seus comerciais passou a ser prioritário na formação do acervo, gerando uma pequena videoteca. Alguns trabalhos da área: $\mathrm{O}$ teleteatro paulista nas décadas de 50 e 60; A história da telenovela; Audiência de telenovela: uma perspectiva histórica; Jornais de Bairro na cidade de São Paulo; História da TV Excelsior; Garotas propaganda; $\mathrm{O}$ rádio paulista no centenário de Roquette Pinto; História da TV Record; Cronologia do rádio paulistano: anos $20 \mathrm{e}$ 30; O fenômeno da longevidade do Garoto Bombril. A equipe mantém uma base de dados sobre televisão e a exposição virtual TV Brasil Ano 50 no site do CCSP.

\section{Fotografia}

Criada em 1993, com a proposta original de ser um centro de referências das atividades desse campo e não um banco de imagens, essa equipe realiza documentação sistemática dos diversos segmentos da Fotografia em São Paulo (no jornalismo, na moda, na publicidade ou em outras manifestações), alimentando bases de dados com informações colhidas na cobertura de todos os eventos afins. Realiza pesquisas sobre temas não registrados na historiografia, que incluem coleta e organização de material documental, depoimentos com fotógrafos e outros profissionais, textos de análise e geração de obras de referência. Alguns trabalhos da área: Fotografia - Cultura; Fotografia paulistana no século XX; Banco de eventos; Banco bibliográfico e artigos da Revista D'Art.

\section{Literatura}

A diretriz tem sido a pesquisa da produção crítica e criativa da literatura brasileira contemporânea, registrada através da docu- 
mentação de obras e autores de prosa de ficção, ensaio e poesia, bem como das tendências do mercado editorial - coleções, antologias, edições especiais, revistas literárias, além de eventos e outras publicações. A equipe participa dos principais eventos literários do país e também organiza exposições, seminários e ciclos de palestras com críticos e escritores. Alguns trabalhos da área: Da literatura à TV; Literatura de ficção em livro de bolso; O escritor brasileiro 1980/1981/ 1982; Movimento de poesia concreta; Crônicas paulistanas; Revistas Literárias da década de 60; Revista Anhembi/50; Cronologia das artes em São Paulo 1975-1995, volume 6 - literatura; O boom literário dos anos 70 e Anuários de literatura.

\section{Música}

Abrange desde trabalhos sobre indústria fonográfica, produção de espetácu-

Resumo: A Divisão de Pesquisas do CCSP é um órgão ligado à Secretaria Municipal de Cultura. Tem origem no IDART, pioneiro na documentação e preservação da produção artística e cultural contemporânea da cidade de São Paulo. Possui equipes especializadas nas áreas de Arquitetura, Artes Cênicas, Artes Gráficas, Artes Plásticas, Cinema, Comunicação de Massa, Fotografia, Literatura e Música. O acervo pode ser consultado gratuitamente no Arquivo Multimeios, que mantém, em sala climatizada, mais de 900 mil documentos entre fotos, fitas de áudio e vídeo, documentos textuais e outros. Realiza ainda exposições, mostras, seminários, ediçōes de livros e da Revista D'Art.

Palavras-chave: pesquisa, documentação, arte contemporânea, cultura, memória, IDART-São Paulo los musicais até composição para a publicidade e depoimentos de personalidades. A partir da década de 90, o principal foco da área passou a ser a composição erudita contemporânea, tanto no aspecto de criação (Dossiê de compositores brasileiros vivos e seus catálogos de obras), quanto no de apreciação pública (levantamento sistemático de obras do século XX, executadas na cidade de São Paulo, organizadas em banco de dados, com informações sobre intérpretes, conjuntos de câmara, orquestras e principais espaços). Alguns trabalhos da área: $\mathrm{O}$ disco em São Paulo; A missão de pesquisas folclóricas; Bibliografia da música brasileira 1977-84; Mário de Andrade e Villa-Lobos. A equipe realiza, periodicamente, depoimentos públicos de compositores com execução de suas obras.

\section{(Art research and memory in São Paulo)} Abstract. CCSP's research division is an agency connected to the Municipal Culture Secretariat. It originates in the IDART, a pioneer in documenting and preserving contemporaneous artistic and cultural production in the city of São Paulo. It has teams that are specialized in Architecture, Scenic Arts, Graphic Arts, Plastic Arts, Cinema, Mass Communications, Photography, Literature and Music. The collection may be consulted free of charge at the Multimedia Archive, which houses, in an air-conditioned room, more than 900 thousand documents, including photos, audio and video tapes, textual documents and other items. It also holds exhibitions, shows, seminars, books and the D'Art Magazine.

Key words: research, documentation, contemporaneous art, culture, memory, IDARTSão Paulo 